\title{
Glucose variability does not contribute to the development of peripheral and autonomic neuropathy in type 1 diabetes: data from the DCCT
}

\author{
S. E. Siegelaar • E. S. Kilpatrick • A. S. Rigby • \\ S. L. Atkin • J. B. L. Hoekstra • J. H. DeVries
}

Received: 3 June 2009 / Accepted: 13 July 2009 / Published online: 12 August 2009

(C) The Author(s) 2009. This article is published with open access at Springerlink.com

Keywords DCCT · Diabetic neuropathy - Glucose variability. Type 1 diabetes

\section{Abbreviations \\ EMG Electromyography \\ MAGE Mean amplitude of glycaemic excursions}

To the Editor: While it is suggested that, in addition to hyperglycaemia, glucose variability can contribute to the severity and development of diabetic neuropathy [1], it is not related to the development of retinopathy and nephropathy in type 1 diabetes $[1,2]$. To determine any additional effect of glucose variability - above that assessed by $\mathrm{HbA}_{1 \mathrm{c}}$ and mean glucose - on peripheral and autonomic diabetic neuropathy, we used the datasets collected during the DCCT (available at www.gcrc.med.umn.edu/gcrc/downloads/dect.html, accessed 23-27 January 2009) [3].

S. E. Siegelaar $(\bowtie) \cdot J$. B. L. Hoekstra $\cdot$ J. H. DeVries Department of Internal Medicine, Academic Medical Center, Meibergdreef 9, Room F4-255,

1105 AZ Amsterdam, the Netherlands

e-mail: s.e.siegelaar@amc.uva.nl

E. S. Kilpatrick

Department of Clinical Biochemistry, Hull Royal Infirmary, Hull, UK

A. S. Rigby

Academic Department of Cardiology,

University of Hull and Hull-York Medical School,

Hull, UK

S. L. Atkin

Department of Diabetes, Hull-York Medical School, Hull, UK
We studied the effect of glucose variability on the main neurological endpoint of the DCCT, i.e. confirmed clinical neuropathy, and on the DCCT-defined secondary endpoints separately: clinical neuropathy, abnormal nerve conduction studies, and abnormal autonomic function [4]. In addition, we determined its effect on the subvariables median motor F-wave latency, sural amplitude, sensory signs and beat-tobeat heart-rate variation (with Valsalva ratio $<1.5$ ), as these variables tend to be the first affected by diabetes. We included only data from baseline to 4 years (autonomic function data) or 5 years of follow-up in the analyses as more than $50 \%$ of the patients did not have records of glucose data after 5 years of follow-up.

We assessed glycaemic variables from seven-point blood glucose profiles collected every 3 months. We included all glucose profiles with five observations or more during the $24 \mathrm{~h}$ period, extrapolating missing values from the surrounding points [5]. Mean blood glucose was calculated by the AUC using the trapezoidal rule [6]. Variability of blood glucose (within-day SD) was calculated as the SD of daily blood glucose around the mean from each quarterly visit and the mean amplitude of glycaemic excursions (MAGE) [7]. Last, we calculated the mean SD from individual glucose data transformed to a symmetric distribution according to Kovatchev [8]. Glucose variability from baseline to 4 or 5 years was assessed as the mean SD and mean MAGE from the first quarter to the 16th or 20th quarter of follow-up, respectively.

The main characteristics of the patients in the group analysed for confirmed clinical neuropathy are listed in Table 1. Of the 1,441 patients in total, 1,160 were included in this specific analysis. Ninety-two patients were excluded from the analysis because they had a positive score at baseline and 189 patients had missing data on confirmed clinical neuropathy at baseline $(n=3)$ or at 5 years $(n=186)$. 
Table 1 Patient characteristics in the group analysed for confirmed clinical neuropathy

\begin{tabular}{|c|c|c|c|}
\hline \multirow[t]{2}{*}{ Characteristic } & \multicolumn{2}{|c|}{ Confirmed clinical neuropathy (5 years) } & \multirow[t]{2}{*}{$p$ value } \\
\hline & Yes $(n=108)$ & No $(n=1,052)$ & \\
\hline Age at baseline (years) & $28.28(6.77)$ & $26.40(7.10)$ & 0.008 \\
\hline Male sex, $n(\%)$ & $52(48)$ & $533(53)$ & 0.38 \\
\hline Diabetes duration at baseline (months) & $79.59(45.62)$ & $68.60(49.79)$ & 0.02 \\
\hline Conventional treatment, $n(\%)$ & $80(74)$ & $517(49)$ & $<0.001$ \\
\hline Primary prevention cohort, $n(\%)$ & $35(32)$ & $503(48)$ & 0.002 \\
\hline $\mathrm{HbA}_{1 \mathrm{c}}(\%)$ & $9.10(1.58)$ & $8.08(1.43)$ & $<0.001$ \\
\hline Mean glucose $(\mathrm{mmol} / \mathrm{l})$ & $13.51(3.33)$ & $11.52(3.78)$ & $<0.001$ \\
\hline MAGE (mmol/l) & $8.00(1.96)$ & $7.55(1.90)$ & 0.02 \\
\hline SD & $4.24(0.89)$ & $4.05(0.93)$ & 0.04 \\
\hline SD TF & $0.75(0.17)$ & $0.81(0.16)$ & $<0.001$ \\
\hline
\end{tabular}

Data are means (SD), unless stated otherwise

For this analysis patients with a positive or missing score for confirmed clinical neuropathy at baseline were excluded (neuropathy $n=92 ;$ missing $n=3$ ) Patients with a missing score at 5 years are also excluded from the analysis $(n=186)$

$p$ values are comparisons between groups (independent samples $t$ test)

SD TF, standard deviation obtained from glucose data transformed according to Kovatchev et al.: transformed blood glucose $=1.794 \times$ $\left([\log \{\mathrm{BG}\}]^{1.026}-1.861\right)$, where $\mathrm{BG}$ is blood glucose in mmol/l [8]

The numbers of participants with data analysed in the other specific neuropathy groups are listed in Table 2. Patients with a positive baseline score on the neuropathy variable studied were excluded from analysis.
Logistic regression analysis adjusted for age (years), sex, disease duration (years), randomised treatment (conventional versus intensive) and prevention cohort (primary versus secondary), showed no effect of glucose variability,

Table 2 Binary logistic regression analysis relating the effect of different glycaemic variables to neurological complications, as defined by the DCCT

\begin{tabular}{|c|c|c|c|c|c|c|c|c|}
\hline \multirow[t]{2}{*}{ Model } & \multicolumn{2}{|c|}{$\begin{array}{l}\text { Confirmed clinical } \\
\text { neuropathy }{ }^{\mathrm{a}} n=108 / 1,160^{\mathrm{c}}\end{array}$} & \multicolumn{2}{|c|}{$\begin{array}{l}\text { Clinical neuropathy } \\
n=148 / 1,113^{\mathrm{c}}\end{array}$} & \multicolumn{2}{|c|}{$\begin{array}{l}\text { Autonomic neuropathy } \\
n=79 / 1,258^{\mathrm{c}}\end{array}$} & \multicolumn{2}{|c|}{$\begin{array}{l}\text { Abnormal nerve conduction } \\
n=207 / 813^{\mathrm{c}}\end{array}$} \\
\hline & OR $(95 \% \mathrm{CI})$ & $p$ value & OR $(95 \% \mathrm{CI})$ & $p$ value & OR $(95 \% \mathrm{CI})$ & $p$ value & OR $(95 \% \mathrm{CI})$ & $p$ value \\
\hline $\mathrm{HbA}_{1 \mathrm{c}}$ & $1.64(1.37-1.95)$ & $<0.001$ & $1.40(1.20-1.64)$ & $<0.001$ & $1.51(1.23-1.85)$ & $<0.001$ & $1.62(1.39-1.90)$ & $<0.001$ \\
\hline AUC & $1.17(1.09-1.26)$ & $<0.001$ & $1.13(1.05-1.21)$ & 0.001 & $1.15(1.05-1.26)$ & 0.003 & $1.15(1.07-1.23)$ & $<0.001$ \\
\hline SD & $1.07(0.83-1.35)$ & 0.67 & $0.95(0.77-1.18)$ & 0.66 & $1.30(0.99-1.70)$ & 0.06 & $1.17(0.96-1.42)$ & 0.12 \\
\hline $\mathrm{SD}\left(\mathrm{HbA}_{1 \mathrm{c}}\right)$ & $0.86(0.67-1.10)$ & 0.24 & $0.82(0.66-1.03)$ & 0.08 & $1.08(0.82-1.44)$ & 0.58 & $0.94(0.75-1.14)$ & 0.46 \\
\hline SD (AUC) & $0.85(0.65-1.10)$ & 0.21 & $0.78(0.61-0.99)$ & 0.04 & $1.09(0.80-1.48)$ & 0.59 & $0.95(0.76-1.19)$ & 0.68 \\
\hline MAGE & $1.06(0.96-1.20)$ & 0.23 & $1.01(0.91-1.11)$ & 0.90 & $1.16(1.03-1.30)$ & 0.01 & $1.07(0.98-1.17)$ & 0.14 \\
\hline MAGE $\left(\mathrm{HbA}_{1 \mathrm{c}}\right)$ & $1.00(0.89-1.12)$ & 0.95 & $0.96(0.86-1.06)$ & 0.37 & $1.09(0.96-1.23)$ & 0.18 & $0.98(0.90-10.8)$ & 0.74 \\
\hline MAGE (AUC) & $1.00(0.88-1.12)$ & 0.93 & $0.94(0.85-1.05)$ & 0.29 & $1.10(0.97-1.25)$ & 0.13 & $1.00(0.91-1.10)$ & 0.93 \\
\hline $\mathrm{SD} \mathrm{TF}$ & $0.14(0.04-0.52)$ & 0.003 & $0.15(0.05-0.48)$ & 0.001 & $0.63(0.13-3.07)$ & 0.57 & $0.16(0.06-0.47)$ & 0.001 \\
\hline SD TF $\left(\mathrm{HbA}_{1 \mathrm{c}}\right)$ & $0.36(0.09-1.37)$ & 0.13 & $0.25(0.07-0.86)$ & 0.03 & $1.42(0.26-7.71)$ & 0.68 & $0.62(0.20-1.87)$ & 0.39 \\
\hline SD TF (AUC) & $0.33(0.08-1.39)$ & 0.13 & $0.26(0.08-0.87)$ & 0.03 & $1.27(0.25-6.29)$ & 0.77 & $0.61(0.19-1.94)$ & 0.40 \\
\hline
\end{tabular}

SD $\left(\mathrm{HbA}_{1 \mathrm{c}}\right)$, SD (AUC), MAGE $\left(\mathrm{HbA}_{1 \mathrm{c}}\right)$, MAGE (AUC), SD TF $\left(\mathrm{HbA}_{1 \mathrm{c}}\right)$ and $\mathrm{SD} \mathrm{TF}(\mathrm{AUC})$ are six distinct models denoting additional adjustment for $\left(\mathrm{HbA}_{1 \mathrm{c}}\right)$ or (AUC)

All models were adjusted for baseline covariates (sex, age, disease duration, prevention cohort, randomised treatment)

$\mathrm{HbA}_{1 \mathrm{c}}$, AUC, SD, MAGE and SD TF represent means from quarterly visits: ${ }^{\mathrm{a}} 1-20 ;{ }^{\mathrm{b}} 1-16$

${ }^{\mathrm{c}}$ Patients with a positive neuropathy score at 5 years/complete analysis group per variable

$\mathrm{SD} \mathrm{TF}$, standard deviation obtained from glucose data transformed according to Kovatchev et al.: transformed blood glucose $=1.794 \times$ $\left([\log \{\mathrm{BG}\}]^{1.026}-1.861\right)$, where $\mathrm{BG}$ is blood glucose in $\mathrm{mmol} / \mathrm{l}[8]$ 
computed as the mean SD and mean MAGE from the seven point glucose profiles from quarterly visits 1-20 (first 5 years), on confirmed clinical neuropathy, clinical neuropathy alone or nerve conduction abnormalities (Table 2). Dividing the variables in quartiles and performing the analyses per randomisation group did not change the outcome (data not shown).

No effect of glycaemic variability on clinical neuropathy was seen, with the exception of a small protective effect of the SD adjusted for AUC (Table 2). In addition, no effect of glycaemic variability was seen on the incidence of sensory signs (SD OR 1.00, 95\% CI $0.82-1.22, p=0.99$; MAGE OR $1.02,95 \%$ CI $0.93-1.12, p=0.69$ ) as well as in separate analysis of the F-wave latency of the median nerve (SD OR 1.12, 95\% CI 0.84-1.49, $p=0.44$; MAGE OR 1.03, $95 \%$ CI $0.90-1.17, p=0.67)$ and the amplitude of the sural nerve (SD OR $1.27,95 \%$ CI $1.00-1.60, p=0.05$; MAGE OR $1.05,95 \%$ CI $0.95-1.17, p=0.34)$. Glycaemic variability seemed to have an effect on autonomic neuropathy, but this effect disappeared when adjusting the model for $\mathrm{HbA}_{1 \mathrm{c}}$ or AUC (Table 2). Analysing both randomisation groups separately also did not reveal a relation over $\mathrm{HbA}_{1 \mathrm{c}}$ (data not shown). Separate examination of the three autonomic function variables showed that only for beat-to-beat heart rate variation during a Valsalva manoeuvre did the effect remain significant when adjusting for mean glucose (SD OR 2.64, 95\% CI 1.17-5.94, $p=0.02$; MAGE OR 1.42, $95 \%$ CI 1.07-1.90, $p=0.02$ ), but not when adjusting for $\mathrm{HbA}_{1 \mathrm{c}}$ (SD OR 1.84, 95\% CI 0.90-3.76, $p=0.09$; MAGE OR $1.30,95 \%$ CI $0.98-1.72, p=0.07)$. There was no effect of glycaemic variability on beat-to-beat heart-rate variation during deep breathing and postural blood pressure testing (data not shown). Transformation of the individual glucose data according to Kovatchev [8] did not alter the results (Table 2).

These results are in line with earlier analysis of DCCT data describing no influence of glycaemic variability on the development or progression of retinopathy and nephropathy [2]. Bragd and colleagues found that glucose variability (SD) was a borderline predictor of the incidence of peripheral neuropathy in 100 patients with type 1 diabetes and with a follow-up period of 11 years $(p=0.07$; HR 1.73, range 0.94-3.19) [1]. Peripheral neuropathy in their study was defined as sensory neuropathy, as indicated by monofilament testing and an abnormal electromyography (EMG) and/or vibration test. This same study showed a significant relationship between SD and the prevalence of peripheral neuropathy $(p=0.03$; OR 2.34, range 1.06-5.20), perhaps suggesting that the nervous system might be particularly susceptible to glycaemic fluctuations [1].

What strengthens our results is that we did not find a relationship between glucose variability and sensory signs or median motor F-wave latency and sural amplitude, the earliest indicators of diabetic neuropathy. As diabetic neuropathy is mostly a small-fibre disease, sensory signs are usually the presenting sign of the disease and they are a stable and reliable measure of disease status or progression [9]. Although EMG studies measure large-fibre function, median motor F-wave latency and sural amplitude are the most sensitive of all EMG measures to detect diabetic neuropathy $[10,11]$.

A limitation of this study is that the variables are calculated from seven point glucose curves by selfmonitoring. Continuous glucose monitoring might detect fluctuations occurring between two measurements that would be missed by self-monitoring of blood glucose. Another difficulty is that the neuropathy variables were infrequently scored. Possibly the DCCT/Epidemiology of Diabetes Interventions and Complications (EDIC) follow-up will provide more endpoints as the same neuropathy variables assessed in the DCCT are measured in years 13 or 14 of its follow-up (2007-2008; www.niddkrepository.org, accessed 23-27 January 2009). These data have not yet been released.

In conclusion, glucose variability was not a risk factor separate from $\mathrm{HbA}_{1 \mathrm{c}}$ or mean glucose in the development of diabetic peripheral neuropathy in the DCCT.

Acknowledgements The DCCT and its follow-up, the Epidemiology of Diabetes Interventions and Complications (EDIC) study, were conducted by the DCCT/EDIC Research Group and supported by National Institutes of Health (NIH) grants and contracts and by the General Clinical Research Center Program, National Center for Research Resources (NCRR). This manuscript was not prepared under the auspices of the DCCT/EDIC study and does not represent analyses or conclusions of the DCCT/EDIC study group or the NIH.

Duality of interest The authors declare that there is no duality of interest associated with this manuscript.

Open Access This article is distributed under the terms of the Creative Commons Attribution Noncommercial License which permits any noncommercial use, distribution, and reproduction in any medium, provided the original author(s) and source are credited.

\section{References}

1. Bragd J, Adamson U, Backlund LB, Lins PE, Moberg E, Oskarsson P (2008) Can glycaemic variability, as calculated from blood glucose self-monitoring, predict the development of complications in type1 diabetes over a decade? Diabetes Metab 34:612-616

2. Kilpatrick ES, Rigby AS, Atkin SL (2006) The effect of glucose variability on the risk of microvascular complications in type 1 diabetes. Diabetes Care 29:1486-1490

3. The Diabetes Control and Complications Trial Research Group (1993) The effect of intensive treatment of diabetes on the 
development and progression of long-term complications in insulin-dependent diabetes mellitus. N Engl J Med 329:977-986

4. The Diabetes Control and Complications Trial Research Group (1988) Factors in development of diabetic neuropathy. Baseline analysis of neuropathy in feasibility phase of diabetes control and complications trial (DCCT). Diabetes 37:476-481

5. Kilpatrick ES, Rigby AS, Atkin SL (2008) Mean blood glucose compared with $\mathrm{HbA} 1 \mathrm{c}$ in the prediction of cardiovascular disease in patients with type 1 diabetes. Diabetologia 51:365-371

6. Rohlfing CL, Wiedmeyer HM, Little RR, England JD, Tennill A, Goldstein DE (2002) Defining the relationship between plasma glucose and HbA1c: analysis of glucose profiles and $\mathrm{HbA} 1 \mathrm{c}$ in the diabetes control and complications trial. Diabetes Care 25:275-278
7. Service FJ, Molnar GD, Rosevear JW, Ackerman E, Gatewood LC, Taylor WF (1970) Mean amplitude of glycemic excursions, a measure of diabetic instability. Diabetes 19:644-655

8. Kovatchev BP, Cox DJ, Gonder-Frederick LA, Clarke W (1997) Symmetrization of the blood glucose measurement scale and its applications. Diabetes Care 20:1655-1658

9. Bril V (1999) NIS-LL: the primary measurement scale for clinical trial endpoints in diabetic peripheral neuropathy. Eur Neurol 41:8-13

10. Sima AAF (1992) Structure-function interactions in the therapeutic response of diabetic neuropathy. J Diabetes Complicat 6:64-68

11. Perkins BA, Bril V (2003) Diabetic neuropathy: a review emphasizing diagnostic methods. Clin Neurophysiol 114:11671175 